\title{
Viaje, biografía, conocimiento - Formación en el exterior de académicas argentinas y diversificación de los estudios de género*
}

\author{
Rafael Blanco**
}

\section{Resumen}

Este artículo analiza las trayectorias de tres académicas argentinas que se desempeñan en los estudios sobre géneros y sexualidades. Como resultado, se destaca la realización de viajes al exterior en tanto puntos de inflexión en la orientación de sus recorridos formativos, sus líneas de investigación y sus inserciones institucionales. A partir de las entrevistas en profundidad realizadas se construyen tres figuras de viaje (militante, antropológico y cosmopolita) con el objeto de explicar las singularidades de estas experiencias, su impacto en cada una de las trayectorias y en el desarrollo y diversificación de esta área de conocimiento en Argentina.

Palabras clave: Trayectorias, Viajes de Estudio, Queer, Activismo, Estudios de Género.

* Recibido el 16 de noviembre de 2016, aceptado el 31 de enero de 2018.

** Universidad de Buenos Aires. CONICET. Instituto de Investigaciones Gino Germani (IIGG). Buenos Aires, Argentina. rafaelblanco@conicet.gov.ar / http://orcid.org/0000-0003-0730-6478 
Travel, Biography, Knowledge: Training abroad of Argentinean female academics and diversification of gender studies

\begin{abstract}
This article analyzes the trajectories of three Argentinean female academics who study genders and sexuality. It highlights trips abroad as turning points in the orientation of their studies, their lines of research and their institutional insertions. Based on indepth interviews, three figures of travel were constructed (militant, anthropological and cosmopolitan) to explain the singularities of these experiences and their impact on each of the trajectories and on the development and diversification of this field of knowledge in Argentina.
\end{abstract}

Keywords: Trajectories, Study Travel, Activism, Queer, Gender Studies. 
Este artículo analiza los viajes al exterior de tres docentes $e$ investigadoras argentinas que se desempeñan en los estudios sobre géneros y sexualidades, en tanto experiencias formativas y de reorientación de sus trayectorias. Se identifica el modo en que el acontecimiento del viaje interviene en la dirección de sus recorridos académicos posteriores, en la formulación de líneas de investigación, de intervención y en la diversificación de las ciencias sociales y humanidades en las universidades públicas. Por ello, los viajes en los que el texto se detiene pueden ser caracterizados con algunos rasgos de lo que Sandra Carli caracteriza como "viajes de conocimiento" (2013:2) en tanto que propician aprendizajes específicos que entran en diálogo con las culturas académicas y políticas de origen y destino, y -podemos agregar- con la experiencia biográfica de cada una de las entrevistas.

El artículo se estructura en cuatro secciones seguidas de unas palabras finales. En primer lugar, se sitúa la investigación en la que este trabajo se enmarca y la emergencia de los viajes como evento significativo en las trayectorias de tres académicas que se desempeñan en un área en crecimiento en Argentina: los estudios sobre géneros y sexualidades. Para dar cuenta del carácter formativo de los viajes analizados recurro a la construcción de tres figuras ${ }^{1}$ que buscan explicar las particularidades, los matices, las diferencias entre cada una de las experiencias analizadas: estas son el viaje militante, el viaje antropológico y el viaje cosmopolita, que estructuran cada una de las secciones siguientes. Estas figuras constituyen un recurso analítico y explicativo que busca singularizar tres modos posibles en que los viajes han operado en la modulación de las trayectorias académicas de las entrevistadas y de su producción de conocimiento. Finalmente, en la última

${ }^{1}$ Las figuras -siguiendo a Roland Barthes- son usos del lenguaje, "retazos de discurso", que tienen por función circunscribir y volver memorable, recordable, reconocible un fluir de acontecimientos, recortados "del discurso que fluye, algo que ha sido leído, escuchado, experimentado" (2002:14). Es tomando esta caracterización que se procede acá a la construcción de tres figuras como recurso analítico. 
sección se destacan los puntos comunes y se retoman los principales hallazgos.

\section{El viaje como un tópico emergente del trabajo de investigación}

El viaje irrumpió como tópico recurrente en los relatos de las entrevistadas en tanto episodio organizador de sus trayectorias. Con Marc Augé, podemos indicar que los viajes producen un ordenamiento del tiempo en términos de una duplicidad, un "antes del acontecimiento o después del mismo" (2012:98). Es por ello que indican "puntos de inflexión" en tanto "marcas perceptivas" que señalan juicios de las entrevistadas acerca del curso que ha tomado su vida (Freidin, 2004:65) y que en este artículo refiere a las nuevas orientaciones que adquieren sus trayectorias académicas.

Los tres relatos analizados fueron seleccionados de un corpus mayor de entrevistas en profundidad realizadas a docentes, investigadores e investigadoras que se desempeñan en los estudios sobre géneros y sexualidades en universidades públicas de Argentina. Forman parte de una muestra intencional conformada para una investigación que se inició en el año 2014 -actualmente en curso- cuyo objetivo es describir y problematizar las tensiones entre itinerarios biográficos, campos disciplinares $e$ instituciones universitarias en los procesos de producción y transmisión de conocimiento en las ciencias sociales y humanidades entre la recuperación democrática en 1983 y el presente. En función de este objetivo, el propósito de las entrevistas fue indagar de manera diacrónica-retrospectiva las trayectorias académicas de las personas entrevistas desde su ingreso a la universidad. Se atendieron como criterios la variabilidad generacional, de disciplinas de origen y de pertenencia institucional, seleccionando a académicos y académicas de tres generaciones (la pionera, la intermedia y la de jóvenes doctores/as) en pos de representar las diferentes líneas de docencia e investigación, disciplinas $y$ trayectorias profesionales. 
Por estudios sobre géneros y sexualidades se refiere aquí a un conjunto heterogéneo de líneas de trabajo orientadas a indagar distintas dimensiones de la vida social atravesadas por el género y la sexualidad, y los modos en que sobre éstas se producen dispositivos legales, morales y sociales (Heilborn y Carrara, 2005). Se caracterizan por la confluencia, no sin conflictos, de articulaciones teóricas, metodológicas y conceptuales de las ciencias sociales y humanidades irreductibles a un único encuadre disciplinar, $y$ tienen por antecedente en Argentina a los estudios de la mujer y el "feminismo académico" (Femenias, 2005).

Los precursores estudios de la mujer se desarrollaron por fuera de las universidades argentinas en el contexto de la última dictadura cívico-militar (1976-1983), impulsados por académicas feministas en centros de investigación privados y Organizaciones No Gubernamentales. Durante los primeros años de la recuperación democrática que se inició en 1983, estos adquirieron mayor fuerza a partir del ingreso a las universidades públicas de militantes, académicas y académicos provenientes del exilio en diferentes países, del exilio interior o "insilio" y de los centros de investigación privados que funcionaron en el período dictatorial (Femenias, 2005; Barrancos, 2007; Gogna, Pecheny y Jones, 2010; Bellucci, 2014), dando inicio a un camino de progresiva institucionalización hasta nuestros días (Blanco, 2018). Transcurridas poco más de tres décadas, estos se han diversificado y articulado con otras áreas de conocimiento y enfoques, siendo hoy no un campo en sentido estricto (debido a la inexistencia de reglas de juego que estructuren el conflicto, la competencia y las posiciones acerca de los distintos modos legítimos de producir conocimiento) sino más bien, como caracteriza Juan Marco Vaggione, un "área en formación" (2012:10).

La investigación de la que este artículo forma parte se desarrolla a partir de la hipótesis de que en Argentina esta área de conocimiento ha tenido un inicio y un desarrollo "desde abajo": no desde políticas institucionales de las universidades $\mathrm{u}$ organizaciones científicas, sino a partir de los itinerarios singulares y grupales de académicas y académicos en articulación con 
diversos grupos y colectivos activistas. Los estudios sobre géneros y sexualidades se fueron haciendo un lugar en el escenario local en diálogo con experiencias que se iban sucediendo en otras instituciones del exterior, en una suerte de traducción de un área en crecimiento y expansión a nivel regional y global con las particularidades de la universidad pública, el sistema científico y los procesos de politización del género y la sexualidad locales.

La hipótesis enunciada es explorada en este artículo a partir de las trayectorias de tres académicas que ocupan un lugar destacado en esta área de estudios debido a su inserción en el sistema científico y universitario. ${ }^{2}$ Las entrevistadas se diferencian entre sí por sus edades, procedencias disciplinares, lugares en que realizan la estancia en el exterior y duración de éstas, pero es el hecho de compartir un mismo "mundo social" en torno a un tipo de actividad específica lo que posibilita analíticamente poner en diálogo sus trayectorias (Bertaux, 2005:23). Además de las entrevistas en profundidad realizadas, se tomaron en cuenta como una fuente de análisis complementaria sus curriculum vitae en tanto documento que da cuenta de las trayectorias objetivadas (García, 2010); esto permitió ubicar temporalmente en las trayectorias algunos hitos significativos que eran referidos en los relatos.

Las figuras que se introducen a continuación respecto del viaje militante, el viaje antropológico y el viaje cosmopolita buscan recuperar la densidad significativa que las experiencias en el exterior tuvieron en sus trayectorias. Si en sus curriculum la referencia a estas experiencias a menudo constituye una referencia más entre otras, un dato objetivado, una certificación, el análisis cualitativo permite en cambio dimensionar el lugar que los viajes tienen como acontecimiento modulador de las trayectorias: es decir, el modo en que estos producen cambios, quiebres,

2 Se trata de académicas que pertenecen a la Carrera de Investigador Científico del Consejo Nacional de Investigaciones Científicas y Técnicas de Argentina (CONICET) y/o que revisten la máxima categoría en el Programa de Incentivos a Docentes-Investigadores del Ministerio de Educación de la Nación. 
desplazamientos en los recorridos singulares, en las inserciones institucionales y en la mutación de los campos de conocimiento de desempeño de las entrevistadas.

\section{El viaje y las articulaciones posibles entre activismo y universidad}

En primer lugar, interesa detenerse en las distintas estancias en Canadá que en la década de 1990 realiza una referente y pionera de los estudios queer en la academia argentina con el objeto de poner en relieve la importancia de estos viajes para el desarrollo de estos estudios a nivel local. Profesora (1986) y Licenciada (1991) en Letras, en el año 1992 la entrevistada accede a una beca para investigar y realizar una estancia en el área de estudios culturales mediante el programa de perfeccionamiento académico International Council for Canadian Studies del Gobierno de Canadá, del que participan las universidades de Toronto, Ottawa y Mc Gil. Luego de aquella beca, los siguientes viajes los realiza costeados mayormente por ella misma -a razón de uno por año hasta 1997- con el objeto de participar en congresos y conferencias, estancias breves y proyectos de investigación. En referencia a la emergente literatura queer, recuerda que en aquellos viajes que realizó "traía todos esos textos" ${ }^{3}$ que encontraba a su paso por las bibliotecas universitarias.

Además de la adquisición de bibliografía novedosa, la entrevistada recuerda haber participado de las polémicas, prácticas e iniciativas que movilizaban estos estudios en la academia de aquel país. Por caso, es durante una estadía en la Universidad de Toronto que sitúa como una especificidad de aquellos debates la tematización de las formas de exclusión en la vida universitaria "de distintas minorías", en sus palabras, debido a las regulaciones heteronormativas, racistas y clasistas que regían en las casas de estudio canadienses. Las discusiones que allí se

${ }^{3}$ En lo sucesivo, las expresiones entrecomilladas constituyen fragmentos de las entrevistas realizadas en el marco del proyecto de investigación referido. 
producían eran retomadas en Argentina para reflexionar y actuar políticamente en los procesos emergentes de politización de la sexualidad, el género y el cuerpo. Según la historiadora argentina Dora Barrancos (2013), los desarrollos norteamericanos de lo queer tuvieron un impacto decisivo y animaron tanto la acción política como la indagación académica en Argentina, en especial por los debates entre estos y los Estudios de la Mujer y de Género con los que -sin embargo- existían puntos de encuentro y formas de institucionalización similares.

Los viajes que realiza la primera entrevistada es posible inscribirlos en una tradición más larga que, en la insularidad de la vida cultural y política de Buenos Aires, alimentaron las lecturas, debates y nuevos repertorios de acción del feminismo local. La historiadora y activista Mabel Bellucci marca que los estudios feministas han estado marcados en Argentina por lo que denomina la impronta de las "viajeras militantes". Caracteriza a estas, en su mayoría, como mujeres profesionales y universitarias con disponibilidad económica para trasladarse al exterior, que en el siglo pasado funcionaron como "peregrinas" que "se desplazaban de un lugar a otro con el propósito de explorar idearios, experiencias y materiales fuera de suelo, para traerlos $e$ instalarlos en beneficio de sus congéneres" (Bellucci, 2014:97). Para esta autora, las viajeras militantes fueron quienes animaron, por caso, la discusión por el derecho al aborto en Argentina a partir de propiciar la publicación de textos, la formación de grupos, la labor docente y de divulgación, sin desatender el activismo -retomando sus palabras- "en las calles". En la medida en que estos viajes son realizados a partir del interés, los recursos económicos, las redes de sociabilidad internacional y la búsqueda de financiamiento específico por parte de quien lo realiza, pero también por la búsqueda de incidir en el escenario local, la figura del viaje militante permite capturar estos rasgos significativos de los viajes que realiza la primera entrevistada a Canadá y que impactan en la especificidad que adquieren, por entonces, los estudios queer en Argentina. 
La entrevistada participó desde sus inicios de ambas discusiones, las locales y las lejanas, en un diálogo entre diferentes culturas académicas y políticas que se fueron anudando con momentos de su propio itinerario biográfico. Formada en la Facultad de Filosofía y Letras de la Universidad de Buenos Aires (FFyL-UBA) entre los años setenta y los primeros años de la recuperación democrática, su trayectoria académica se fue configurando entre el espacio universitario y el activismo por los derechos humanos. De militancia en la Juventud Universitaria Peronista como estudiante, antes de la última dictadura, la academia de los años ochenta (luego del Terrorismo de Estado, las desapariciones y los diferentes exilios que oscurecieron la vida universitaria) se le presenta como un escenario relativamente ajeno para la actividad política, tras su regreso a las aulas luego de interrumpir los estudios entre 1976 y 1982. En sus palabras, la universidad "no era ya un espacio de pertenencia", señalando el contraste con su experiencia anterior. Esto se modifica cuando irrumpe en la escena universitaria local la disidencia sexual como locus político y objeto de debate académico.

Conforme avanza la década hacia los años noventa, comienza a organizarse un grupo de estudiantes en FFyL, de "jóvenes militantes de distintas carreras", con quienes tiene una diferencia de edad de al menos diez años. Estos habían ya incorporado el ethos democrático que caracterizó a la militancia juvenil de aquellos años (Blanco y Vommaro, 2017) y se diferenciaban de la generación de la entrevistada por pertenecer, según ella misma identifica, a "una cultura política diferente" que articulaba adscripciones solapadas entre el espacio universitario y "los movimientos $\mathrm{LGBT}^{4}$, que en ese momento era fundamentalmente la CHA" (en relación a la Comunidad Homosexual Argentina).

En 1991 la entrevistada es invitada por estos jóvenes a participar de un ciclo de conversaciones extracurriculares, de

4 Sigla que refiere a Lesbiana, Gays, Trans y Bisexual, de uso corriente en este siglo y que en la entrevista tiene un uso anacrónico. 
debate, en Filosofía y Letras los días sábados, con el objetivo de conformar un grupo de militancia. Este grupo será denominado Colectivo Eros (1993), y constituye un antecedente del Área de Estudios Queer y Multiculturalismo (1996) en los que la entrevistada participa desde su fundación junto a otros académicos y activistas. Si "Eros" remite a los años setenta, por relación al grupo homónimo del que participaba el poeta, militante y sociólogo argentino Nestor Perlongher, queer -en cambioconstituía un nombre del presente: un término en otra lengua, en auge y apropiado de la academia de Estados Unidos y Canadá, que venía a nombrar un repertorio militante distinto al de los países del norte para inscribirse en una clave local. En otras palabras, los viajes propiciaron un intercambio y un juego de contrastes que van a ir delimitando los significados y prácticas de lo queer acá y allá.

En la reconstrucción genealógica de lo queer en Argentina, que realiza Cecilia Palmeiro (2014), la autora sostiene que fue en estos espacios referidos en el ámbito de la Facultad de Filosofía y Letras de la UBA que este término fue "importado" a la Argentina en tanto perspectiva teórico-crítica y como plataforma militante para el activismo de la disidencia sexual local. Fue producto de una reformulación vernácula que invitaba tanto a activar cultural y políticamente desde la Facultad a la vez que a "intervenir en luchas políticas en la ciudad de Buenos Aires" (Palmeiro, 2014:15). De aquellos viajes la entrevistada recuerda las especificidades que en cambio lo queer adquiría en el debate universitario en aquel país:

en ese momento lo articulaban con raza, y en la academia canadiense ello buscaba impactar en las prácticas institucionales: la política de cuotas como modalidades de acceso por raza, por género, por orientación sexual, por lugar de nacimiento. ${ }^{5}$

${ }^{5}$ Entrevista realizada a referente y pionera de los estudios queer en la academia argentina realizada en julio de 2016. 
Así, en Canadá los debates en la academia -recuerda- buscaban volver la mirada a la propia institución universitaria, "que se tuvieran que enfrentar a que esas voces, miradas, cuerpos y subjetividades no estaban en la universidad".

En cambio, la apropiación local de lo queer articulaba diversas tradiciones que no se reducían a un tema de "minorías". Aquí se inscribía en el ideario de Perlongher y el primer colectivo Eros, en la búsqueda de articulación entre las luchas de clase, de género y sexualidad "en un movimiento contracultural que se erigiera contra todas las formas de explotación, exclusión, represión y discriminación, en una alianza entre la izquierda revolucionaria y el feminismo" (Palmeiro, 2014:15). A su vez, lo queer en términos locales se proponía vincular a distintos movimientos contra la discriminación, la represión y las luchas LGBT junto a activistas y artistas, estudiantes en diferentes instancias de su formación e intelectuales provenientes de la academia y de los movimientos sociales. Es decir, su recepción en Argentina buscó conectar cierto locus disruptivo en el ámbito académico con tradiciones de más larga data, articulación que situaba al ámbito universitario como parte de las luchas sociales, especialmente respecto de los procesos represivos que se acentuaron en Argentina entre los años noventa y el año $2001{ }^{6}$ Distintas iniciativas del colectivo político-académico que integra la entrevistada se realizaron en aquellos años retomando demandas y reivindicaciones y en alianza con el activismo travesti y trans, con jóvenes de sectores populares, trabajadores precarizados y desocupados, o con quienes ejercían la prostitución.

El juego de comparaciones permitió advertir otro rasgo de la singularidad argentina -y latinoamericana- que iba asumiendo lo queer. que la lucha contra la represión era una lucha de los

${ }^{6}$ Ese año finaliza con la renuncia del entonces Presidente de la Nación, Fernando De la Rua (UCR-Alianza) tras sólo dos años de gobierno, en medio de un clima de convulsión social y aguda crisis económica que se prolongó por más de dos años. 
derechos colectivos y no una lucha por los derechos de determinados grupos. En sus palabras,

Mientras en Europa y Estados Unidos a partir de un concepto liberal de multiculturalismo los derechos políticos se constituyen en términos de lobby o grupos de interés, fundamentalmente a nivel parlamentario, a nivel empresarial, [en cambio] en América Latina esa lucha no puede ser sino territorial porque el tipo de exclusión política que produce la represión, politiza la pobreza. Y esa es una convicción que teníamos desde los años ' $90 .{ }^{7}$

Además del contacto con un renovado corpus textual, de lenguajes, repertorios de acción, los viajes fueron habilitando, por último, una reflexividad particular sobre el devenir académico de la entrevistada, sobre su activismo, y respecto de su ámbito inmediato de inscripción: la universidad pública, la UBA. Su relato da cuenta del juego de las diferencias entre cómo resonaba la irrupción del término queer en Argentina y Canadá, los sentidos y prácticas que movilizaba en la trama institucional de las universidades públicas canadienses y las locales, y el modo en que era entendida por sus pares su adscripción a la emergente Área de Estudios Queer que estaba, colectivamente, fundando. "Aquí se nos acusaba de ser liberales, de ser políticamente correctos" $\mathrm{y}$, fundamentalmente, "de proponer una tolerancia liberal". El ir y venir de norte a sur del continente, esa deriva efecto de los viajes anuales, la relativa distancia y la mirada comparativa van a posibilitar una producción de sentido sobre el propio medio académico a partir de las interacciones y situaciones de las que participa en ambos contextos. En respuesta a esas críticas, sostiene: "había algo que tenía que ver sin duda con la cultura política argentina. Se podía ser universitario en aquel momento sin saber que se estaba a pocas cuadras de una zona roja", que desde

7 Entrevista realizada a referente y pionera de los estudios queer en la academia argentina realizada en julio de 2016. 
entonces y hasta nuestros días constituyen territorios de frecuente accionar represivo policial.

El surgimiento y desarrollo del Área Queer constituyó una experiencia pionera y marcó un hito en la universidad pública argentina. Como dijimos, fue posibilitada, más que por designios o iniciativas institucionales, por los itinerarios activistas y académicos singulares y el contacto fluido con experiencias que ocurrían en otros territorios. La figura del viaje militante -figura que actualiza la caracterización de las "viajeras" que conformaron la arena de discusión del feminismo local desde inicios del siglo pasado- busca capturar de la trayectoria de la entrevistada el modo en que sus viajes permitieron conectar, situar y diferenciar causas militantes y repertorios de acción en la academia argentina con el objeto de articular con actores, colectivos, saberes y procesos de politización. Por último, esta figura se diferencia de las formas de movilidad profesionalizadas propias de este siglo, moduladas por instituciones, financiamientos y tiempos específicos, que en nuestros días ritualiza la estancia en el exterior como pasaje entre momentos de formación en la propia trayectoria, tal como lo trabajamos en las siguientes dos figuras: el viaje antropológico y el viaje cosmopolita.

\section{El viaje y la reinvención de la trayectoria académica}

La segunda entrevistada, Magíster en Investigación en Ciencias Sociales (2007) y Doctora en Ciencias Sociales (2009), expresa como "un quiebre" la estancia de investigación que en 2009 realiza en la Universidad de las Islas Ballares (España). A diferencia de la trayectoria referida en el apartado anterior para caracterizar el viaje militante en los años noventa, se trata de una Socióloga egresada de la UBA (2001) que se desempeña durante el proceso de formación doctoral (2003-2008) y posdoctoral (20082010) como becaria del CONICET. Ello implica que atraviesa su recorrido académico con financiamiento para realizar posgrado en el marco de la consolidación y regularización del sistema nacional de ciencia y técnica argentino que se produjo a partir del año 
2004, y de los procesos de movilidad académica propia de este siglo.

Como producto de la estabilidad en la financiación estatal y la institucionalidad del Consejo (convocatorias periódicas a becas, subsidios e ingresos a la Carrera, además de una fuerte jerarquización salarial respecto de períodos anteriores), la entrevistada accede a la realización de una estancia en el exterior luego de obtener una beca específica para ello del CONICET. Parte a España con un plan inicial de estancia de tres meses, de febrero a mayo de 2009; este destino es elegido debido al idioma común y a su doble ciudadanía argentino-española.

La llegada a España le depara una nueva posición en el espacio académico, que no es sin un cambio en su jerarquía: rápidamente accede a un cargo de Profesora. Dada su condición de ciudadana de aquel país, tiene la posibilidad de presentarse a un concurso docente: "llevo los papeles, concurso y me lo gano". Ese cambio fue acompañado con una mejora económica, por lo que el desplazamiento en la jerarquía que depara el viaje no fue sólo en términos de posición en la vida universitaria sino también económica, y que la entrevistada sintetiza, en relación con su salario, con la expresión "ganaba en euros".

Como rasgo significativo de este desplazamiento, es posible indicar que produce una diferencia respecto de su trayectoria anterior. El salario en moneda europea contrasta no sólo con los cinco años anteriores en que había cobrado estipendio como becaria del sistema científico (a diferencia del salario, se trata de un contrato con remuneración sin beneficios de seguridad social), sino también con las dificultades económicas que atravesó entre los años noventa y la crisis posterior al año 2001. En otras palabras, la experiencia de España se produce por contraste no sólo con el período doctoral sino también con los años anteriores al ingreso como becaria de investigación. Aquellos años habían producido un proceso de movilidad descendente en su familia: un hogar de clase media "que se pauperizó, se transformó en una clase trabajadora o sin trabajo, o con trabajo informal y eso le pasó a mi familia"; había comenzado a trabajar siendo estudiante 
secundaria, y, con el nacimiento de su única hija en el 2001, sorteó el desempleo mediante la obtención de un plan social estatal (denominado "Jefes y Jefas de Hogar") como forma transitoria de subsistencia.

En este caso el viaje propicia un punto de inflexión en su trayectoria debido a su cambio de posición en el ámbito académico entre su lugar de origen y el de destino, y podemos caracterizarlo bajo la figura del viaje antropológico. Esta caracterización busca trascender la acepción del viaje en su significado corriente más habitual, es decir, la del traslado físico "que se hace de una parte a otra por aire, mar o tierra" 8 para indicar otras transformaciones que no se agotan en el hecho del traslado físico. Es Claude Lévi-Strauss en Tristes trópicos quien define a la experiencia del viaje como un desplazamiento no sólo en el espacio sino también "en el tiempo y en la jerarquía social" (2006:112). Son estas tres coordenadas las que el viaje transforma; de ahí que interesa tomar la figura del viaje antropológico para referir a la estancia como un acontecimiento que puede propiciar una reinvención de la trayectoria académica.

Intervienen en ese desplazamiento en el espacio, el tiempo y la jerarquía durante la estancia, una serie de acontecimientos. En primer lugar, el hecho de producirse ésta en el momento de la formación posdoctoral. La etapa inmediata posterior a la obtención del título de Doctor abre, para quienes continúan en la tarea de investigación, una serie de interrogantes en torno a la continuidad o variación de la línea de investigación, al cambio o la permanencia en las inserciones institucionales, del vínculo con la dirección del trabajo y, grosso modo, por la aspiración a un cambio de posición en el ámbito de desempeño (Remedi y Blanco, 2016). Dicho en otros términos, el pasaje entre doctorado y la formación de posdoctorado es un tiempo propicio para la reorientación de la propia trayectoria, y especialmente en una dirección que posibilite un cambio respecto de la pertenencia a un

8 Tal la entrada de la Real Academia Española a la definición del sustantivo "viaje". 
equipo en un rol subordinado o poco jerarquizado. Se trata, en efecto, de la búsqueda de singularización o construcción de un nombre propio, algo fundamental en el terreno de las ciencias sociales y humanas como lo hizo notar Pierre Bourdieu (2012) en su caracterización del homo academicus. La nueva posición como Profesora en España produce entonces un movimiento en la jerarquía, en términos no sólo materiales sino también simbólicos, que marcan uno de los reposicionamientos, de los ascensos a los que Lévi-Strauss se refiere en tanto "subir o descender algunos grados en la escala de los status" (2006:112) y que propician los viajes.

En segundo lugar, en parte por esta situación de pasaje entre ciclos de formación, la ida a España impacta en su jerarquización académica debido a que se produce en un momento de relativa incertidumbre, en un tiempo de espera respecto de su inserción futura en el espacio académico en Argentina. En el marco del proceso referido de acelerada profesionalización del medio científico local, el momento posterior al doctorado, para quienes se proponen continuar con el oficio de investigación, supone un tiempo preparatorio para el ingreso a la Carrera de Investigador Científico dentro del CONICET, organismo que concentra el financiamiento de la investigación en el ámbito de las Universidades Públicas. "Yo estaba terminando la beca postdoctoral, me había presentado a [el cargo de Investigadora de] CONICET y no sabía si salía". Es en ese contexto que la entrevistada viaja a Palma de Mallorca.

Pero además de un cambio en la jerarquía, la estancia es, como viaje antropológico, un momento que anticipa un tiempo futuro, un desplazamiento hacia adelante en el tiempo. La renovación de lecturas, la experimentación en el terreno de la docencia, $y$, fuertemente, la articulación de la intervención

9 A partir de los cambios suscitados desde el año 2004 en materia de política científica y tecnológica, las universidades públicas son el principal espacio de investigación ya que representan el lugar de trabajo del $40 \%$ de los investigadores/as y becarios/as del CONICET (Oregioni y Sarthou, 2013). 
feminista en el propio espacio universitario -algo hasta entonces relativamente escindido en su devenir académico- al regresar van a marcar un nuevo sentido, como significación, pero también como dirección en su trayectoria. Como en el caso de la primera entrevistada, el hecho de trasladarse a otra universidad posibilita un contacto con bibliografía, debates y experiencias novedosas del trabajo académico. Este movimiento de "circulación de objetos de estudio, temáticas, metodologías y tradiciones científicas entre países llamados centrales y países considerados periféricos" es característico de los procesos de movilidad académica (Kreimer en Spivak y Hubert, 2012:90). La entrevistada caracteriza como "fundamental" al hecho de "estudiar afuera" para quien se forma en el oficio de la investigación: estar en España, en palabras de la entrevistada, le permitió reconocer "el provincianismo de las teorías, de los métodos" que, no sin ironía, caracteriza como "peligrosísimo".

Uno de los aprendizajes al que refiere la entrevistada es acerca de la utilización de autores desconocidos hasta entonces: el feminismo islámico y el católico, la lectura en auge de, por entonces, Beatriz Preciado ${ }^{10}$ y la producción ibérica de la línea del feminismo de la igualdad. Pero también refiere a las metodologías, $y$, en su formación como socióloga, el fuerte trabajo con estadísticas: "aprendí mucho sobre demografía, las hipótesis que arman al combinar métodos". Ello se ve reforzado por otro rasgo del momento posdoctoral, período que marca un nuevo régimen de lecturas que tiene como rasgo alejarse de "ese pragmatismo de la tesis, de leer muy en función de la investigación", en sus palabras, propio del período de formación doctoral. La estancia habilita entonces la reformulación de temas y de la propia dinámica de trabajo, "fue un momento importante para estudiar", recuerda, en relación con el contacto con nueva literatura feministas, su descubrimiento de la teoría queer y, también, de la relectura con nuevas preguntas de autoras clásicas ("estudie mucho a Nancy Fraser que era la moda allá").

${ }^{10}$ Hoy Paul B. Preciado. 
En la prefiguración de ese tiempo futuro, la docencia también es objeto de un renovado interés. Según recuerda, sus alumnas hablaban "incorporando los derechos, incorporando el discurso feminista, las cuestiones identitarias, el tema de la sexualidad, del deseo". Su enunciación procura un contraste en el espacio para caracterizar los aprendizajes diferenciales durante el viaje: "eso que nosotros acá estudiamos, allá estaba en las prácticas". La experiencia en la universidad ibérica propicia, como en el caso anterior, una reflexividad crítica respecto del propio espacio de formación y desempeño académico anterior, por contraste con el "aprendizaje de esas experiencias" o el "militar esa teoría". En sus palabras,

Hacíamos clases, armamos un seminario en la universidad en un aula y pusimos una cama y dimos el seminario arriba de una cama. Hacíamos cosas muy locas, raras. Trajimos a una teóloga feminista a hablar en una cama semi-desnuda. Bueno, cosas muy raras hacíamos, y nos divertíamos haciéndolas. Acá es todo solemne. ${ }^{11}$

Esa progresiva transformación de las formas académicas, la exploración en el terreno de la docencia, las nuevas lecturas que se abren en la tarea de investigación, el vínculo con las estudiantes en los cursos y las relaciones entre teorías y experiencias permite también anudar un rasgo ya presente en su biografía pero que adquiere una nueva significación en este viaje: la política, que ya había estado presente en prácticas de militancia especialmente a partir de la crisis argentina de 2001, pero relativamente escindida de su devenir académico. Si bien durante su formación universitaria cursó "todas las materias 'de género' disponibles", fue su participación en un grupo de lecturas por fuera de la universidad, en la Librería de las Mujeres (una Asociación Civil fundada en 1995 de tradición feminista), que la entrevistada reconoce su mayor formación en esta área: en aquel grupo

${ }^{11}$ Entrevista a académica argentina especialista en violencia de género en mujeres, lesbianas y mujeres trans estudiantes, realizada en abril de 2014. 
aprendió "a pensar como feminista". Quienes lo coordinaban, una filósofa y una docente de Letras, encarnaban para la entrevistada otra figura de académicas respecto de sus docentes de la universidad, "una línea académica militante" que van tramando el perfil que busca forjar para sí misma: "quería hacer investigación para transformar".

En España comienza a tomar forma la posibilidad para sí de hacer converger militancia y trabajo académico. Su llegada se produce durante el segundo gobierno de José Luis Rodríguez Zapatero (2004-2011), quien había llevado adelante una importante agenda feminista, aunque en el período en que la entrevistada recala en el país ibérico los recortes y el ajuste estructural se estaban comenzando a producir impulsados por el mismo gobierno socialista. "Vi todas esas negociaciones, que en realidad era un Gobierno feminista, estaban todas las mujeres progresistas en el Gobierno de Zapatero". Ese "escucharlas", "verlas", siguiendo con sus palabras, "estudiar mucho la política feminista en el Estado", analizar "el camino político que hicieron las feministas progresistas" y la experiencia de las mujeres que "venían conduciendo en el Estado español" y que dejaron su marca en el gobierno del Partido Socialista Obrero Español (PSOE), le permitió imaginar para su propio trabajo como académica la posibilidad de la gestión:

Para mí la experiencia de España fue un quiebre, porque yo era así como una vieja feminista que había que ir [por ejemplo] por la ley de despenalización y legalización del aborto... eh, y me parece que hay que jugársela de otra manera, y de eso tuvo mucha "culpa" la experiencia española, de que son arriesgadas, que también se daban las condiciones para hacer todo eso, en ese momento. ${ }^{12}$

Debido a ese cargo que adquiere rápidamente al llegar a la Universidad de las Islas Ballares, aquel viaje originariamente de

${ }^{12}$ Entrevista a académica argentina especialista en violencia de género en mujeres, lesbianas y mujeres trans estudiantes, realizada en abril de 2014. 
tres meses se prolonga por un período de dos años. Durante ese lapso, realiza idas y vueltas entre Argentina y España con hiatos que no se prolongan más de seis meses, dado que debe compatibilizar el trabajo en el país Ibérico con su posición como becaria posdoctoral, primero, y como Investigadora de CONICET luego (ya que su ingreso es aprobado), pero también con la maternidad y los afectos, aspectos invisibles de los curriculum vitae pero fuertemente estructurantes del devenir académico (Remedi y Blanco, 2016). En ese "entre países" de dos años de duración, la entrevistada concursa y accede a un cargo de Profesora Adjunta en una universidad estatal del Área Metropolitana de Buenos Aires, ingreso que se efectiviza en marzo de 2011. Es entonces cuando se reestablece por completo en Argentina $y$, tres años después, comienza a coordinar un Programa contra la Violencia de Género en esa institución -pionero y modelo de experiencias que desde entonces han comenzado a replicarse en otras instituciones- y un posgrado en salud Sexual y Reproductiva desde un enfoque de género y derechos humanos.

La transformación de su trayectoria se produce en aquel viaje: en ese movimiento en las jerarquías académicas, en el espacio y también en el tiempo. Articular con la comunidad, el territorio próximo al campus universitario, interpelar a quienes estudian en esa casa de estudios como así también a los pares y autoridades, van a ser rasgos que la entrevistada va a destacar de su propia trayectoria a partir de aquel momento. $\mathrm{Si}$ "hacer gestión", en sus palabras, era una inquietud que estaba presente desde antes de su viaje, ésta toma nuevos bríos a partir de aquella experiencia en la que se habían prefigurado rasgos de un tiempo futuro.

\section{El viaje y la reflexividad sobre experiencia biográfica en la cultura académica}

La última figura a detenerse es la del viaje cosmopolita. Sin desestimar algunos rasgos presentes en las figuras anteriores -tales como la posibilidad de acceso a otra literatura, enfoques de 
investigación, repertorios activistas, saberes y una renovada sociabilidad académica- mediante la caracterización "cosmopolita" interesa destacar la dimensión conflictiva que implica el contacto con personas desconocidas con quienes entramos en contacto durante un viaje.

El filósofo Kwame Appiah denomina "curiosidad cosmopolita" a la experiencia del aprendizaje que se produce al "sentirnos intrigados por las maneras alternativas de pensar, sentir y actuar" (2007:137). Es esta curiosidad a la que refiere una entrevistada, Profesora (2002) y Doctora en Historia (2009), quien contrapone el "turismo académico" con la posibilidad de viajar, "ver otras culturas, conocer otras personas" para ubicar en su relato una experiencia que califica como "muy reveladora".

Historiadora feminista dedicada a temas de sexualidad, la tercera entrevistada narra un viaje a Ciudad de México en 2009 para participar de un encuentro centrado en temas de religión. El hecho de no tener un conocimiento y un itinerario de trabajo académico en los estudios sobre religión, sino un cruce problemático a partir de los temas que por entonces trabajaba marcaba, según recuerda, el desconocimiento de "muchos textos que eran básicos" entre quienes sí adscribían a aquel campo. Este relativo desconocimiento de las reglas del intercambio en un área de producción de conocimiento en las ciencias sociales frente a sus pares la ubicaba en una situación de relativo extrañamiento. Su desempeño desde el ciclo de formación doctoral que había finalizado ese mismo año era, en cambio, en torno a "cuestiones de sexualidad" en la historia. El plan de trabajo con el que aplicó para acceder a aquella estancia fue acerca de los derechos sexuales y reproductivos "pero preocupada por la iglesia".

En el encuentro sobre laicidad en México participaron tanto activistas como académicos y académicas de distintas partes de Iberoamérica con el propósito de mejorar las estrategias de difusión y promoción de los derechos humanos, las libertades civiles y, en particular, los derechos sexuales y reproductivos. Durante diez días se realizaron seminarios de discusión y talleres de investigación, reflexión y análisis, en las conferencias 
magistrales que se alternaban con los espacios de discusión de menor escala, participaron referentes del feminismo latinoamericano como Marta Lamas o la historiadora Joan Scott, autora de un texto fundamental en los estudios sobre géneros y sexualidades: El género: una categoría útil en el análisis histórico. Los espacios de formación y los debates tenían por objeto producir, al final del encuentro, un texto ensayístico acerca de los temas del curso, que se estructuraban en cuatro grandes áreas: principios de la laicidad; Estado laico, derechos humanos y democracia; laicidad, derechos sexuales y reproductivos; y retos actuales de la laicidad.

La atención a la Iglesia en su trabajo académico, punto de conexión con los temas del encuentro, anudaba fuertemente en su propia biografía ya que la entrevistada se reconoce católica en un medio social -el ámbito científico, las ciencias sociales y humanidades- menos habituado a este tipo de adscripciones. Hasta llegar a la carrera de Historia en la UBA, su formación anterior la había realizado en colegios parroquiales. Como fue analizado en un trabajo anterior acerca de las conexiones entre biografía y producción de conocimiento en las trayectorias de mujeres académicas (Blanco, 2016), el encuentro con los estudios feministas y de género durante su formación en el profesorado había producido un primer impacto en su devenir académico a partir de dos movimientos. Por un lado, estos habían propiciado una nueva narrativa, una lectura retrospectiva acerca de las mujeres de su familia y de sí misma, de las mujeres de sectores trabajadores no universitarios del que provenía, a partir del entramado de inteligibilidad provisto por el léxico, los corpus y la cercanía o lejanía con los hitos que los estudios de género y feministas ubican en la historia ( $y$ en especial la "revolución sexual" de los años sesenta). Por otro, el encuentro con estos estudios había reorientado el sentido de su trayectoria, ya que el ciclo de formación de posgrado y de inserción en el sistema científico se realizó a partir del desarrollo de una línea de investigación centrada en los discursos y experiencias en torno a la regulación de la natalidad en la segunda mitad del siglo XX en 
Argentina. No obstante, su identificación como católica y las implicancias que ello tenía en su trayectoria académica hasta entonces aparecían menos problematizadas hasta entonces que el género y la clase.

Es en este marco que el viaje constituyó para la entrevistada un punto de inflexión ("ese encuentro me cambio mucho", en sus palabras) en la medida en que propició una reflexividad no sólo sobre su propia biografía sino también sobre su ámbito de desempeño, sobre los mandatos del medio académico y sobre las formas de regulación que rigen las trayectorias académicas. En la conversación con otros y otras desde aquella breve estancia la entrevistada reconoce un punto de conflicto en términos de interpelación personal; interpelación que materializa una posición de "confrontación frente a lo religioso" (García Somoza y Irrazábal, 2014:136) característica de los grupos militantes feministas, de la diversidad sexual y académicos latinoamericanos. En palabras de la entrevistada,

Me empezó a hacer ruido esto del antitotalitarismo. La diferencia entre ser anticlerical y ser laico, algo que se notaba mucho. El activismo latinoamericano estaba ahí y era como "bueno, salgamos a quemar las iglesias", algo que a mí me interpelaba mucho en mi identidad religiosa. ${ }^{13}$

Para Appiah (2007:19), cosmopolitismo es "el nombre del desafío" que supone tanto el interés por lo universal -que en este caso traza el horizonte normativo de la laicidad- como así también el respeto por las legítimas diferencias que moviliza el encuentro entre extraños. En otras palabras, el viaje materializó el desafío que suponía para la entrevistada el desarrollo de una trayectoria que articulara tanto su inscripción a los estudios de género y como historiadora feminista, con su reconocimiento como católica.

Este conflicto entre distintos procesos de identificación parecería venir a señalar las formas de adscripción correctas,

${ }^{13}$ Entrevista a académica argentina especialista en discursos y representaciones sobre la liberación femenina realizada en mayo de 2014. 
esperadas o deseables, que operarían como un ideal regulatorio en el espacio académico. En la experiencia de la entrevistada, este mandato se expresaba en el enunciado más o menos explícito de "no podes ser católica y feminista", el rechazo por lo religioso, pero también en otros que señalan el modo de encarnar una trayectoria como académica feminista: "no podes ser monógama y creer en la revolución sexual", o las discusiones en torno a la maternidad y la opresión que conectaban con la propia experiencia de ser madre ("me generan, en lo personal, mucha movilización. Y digo: 'será que yo no soy liberada").

Si interesa señalar la importancia que esta estancia tiene en el relato del devenir académico de esta entrevistada y ubicarlo bajo la figura del viaje cosmopolita es debido a que -al igual que en el viaje militante o el viaje antropológico referidos- tiene un fuerte efecto en el curso que adquiere su trayectoria posterior. Pero difiere en el hecho de que su especificidad radica en cierta dificultad para "desarrollar el hábito de la coexistencia: la conversación en su sentido más antiguo, la convivencia, la asociación" en palabras de Appiah (2007:22).

No es sin esta dificultad, del encuentro con ese lugar y estos mandatos que producen una interrogación de su propia pertenencia a la academia, que progresivamente esta investigadora irá modificando su línea de investigación. En otros términos, el viaje colaboró de un modo decisivo en la reformulación de su labor académica. En su línea de trabajo se produce un desplazamiento desde el siglo XX al presente, y de la "revolución de la píldora" y los métodos de regulación de la natalidad -temas de su tesis doctoral- a los discursos y a las prácticas de la liberación emergentes hoy, como línea del trabajo posdoctoral. La pregunta, en sus palabras, "por las formas en que se entiende la liberación femenina ahora", tanto para las feministas pero también "para las mujeres jóvenes no feministas que también tienen un discurso de liberación" va a ir constituyéndose como un tema central en su trayectoria, buscando no sólo mapear los bordes, limitaciones y discursos normativos que regulan las experiencias de mujeres sino también atendiendo 
a la heterogeneidad de posiciones existentes en el interior desde las identificaciones religiosas.

\section{Palabras finales}

El interés por los viajes en las trayectorias académicas fue el emergente de un trabajo orientado a indagar el modo en que los estudios sobre género se fueron configurando en Argentina desde la recuperación democrática. El desembarco y la diversificación de estos en las universidades públicas durante los años ochenta, lejos de ser el resultado de planificaciones institucionales, ha tenido una fuerte impronta "desde abajo", de quienes, proviniendo de distintas disciplinas fueron realizando cruces, articulaciones por dentro y por fuera de la academia, y, desde este lugar, fueron recreando el espacio universitario y científico.

En este sentido, las referencias a los viajes fueron traídas a la escena de la conversación por las académicas entrevistadas, quienes recurrían a narrar estas experiencias en el exterior como recurso para dar cuenta de puntos de inflexión en su formación, su inserción en instituciones y los cambios en sus líneas de investigación, de activismo, de intervención. Las tres figuras de viaje que acá caracterizamos -militante, antropológico o cosmopolita- tratan de viajes de conocimiento, "de aprendizaje" ya que modifican a quienes los hicieron (Sarlo, 2004:26). Como fue dicho para los tres casos, esos aprendizajes se producen en parte debido a la reflexividad que los viajes propician, como proponen para el campo científico Ana Spivak y Matthieu Hubert, para quienes los actores "producen sus discursos analizando experiencias de la vida profesional y estableciendo lazos entre ámbitos y contextos de trabajo, y las maneras de pensar y hacer investigación" (2012:91).

La reflexividad aludida no se restringe al obrar académico, sino que se extiende a un sinfín de órdenes de la vida cotidiana que exceden esta esfera. Como toda figura que busca representar, capturar una imagen del complejo discurrir de un itinerario singular, las figuras del viaje militante, antropológico y cosmopolita 
son incompletas. No logran, por caso, dar cuenta de dimensiones centrales en las biografías de algunas de las entrevistadas, como lo es la experiencia de la maternidad en la trama de los viajes referidos y que requiere una mayor indagación. Tampoco capturan otros aprendizajes que se producen en los viajes: moverse en una ciudad, los vínculos afectivos que se trazan marcados por el deadline de la vuelta o, también, el aprendizaje de la soledad. Sin poder saldar estos recortes de este artículo, vale decir que las narrativas sobre los viajes de las entrevistadas sugieren, explicitan y despliegan numerosas referencias en estas direcciones que ameritan una mayor atención en trabajos futuros.

No obstante, las figuraciones construidas aquí permiten poner en escena elementos que intervienen fuertemente la construcción de sus trayectorias y que quedan a menudo opacados, dado que en el actual proceso de profesionalización académica se priorizan, evalúan y consignan los puntos de llegada, los productos, el volumen de una producción que se materializa en un curriculum o en las bases de datos. Como señala Susana García, limitarse a una mirada de los "puntos de llegada", deja "poco o ningún lugar a los recorridos" y a la comprensión del proceso "en el que un individuo 'se va haciendo' académico" (2010:4). Los relatos aquí analizados y las figuras de viajes referidas buscan dar cuenta de algunas de las dimensiones que implica el devenir académico: proceso que envuelve cambios en las líneas de trabajo, en las inserciones y modos de habitar las institucionales, en las articulaciones con colectivos y actores extrauniversitarios y como dimensión a menudo invisibilizada- en la trama íntima de las propias biografías.

\section{Referencias bibliográficas}

APPIAH, Kwame. Cosmopolitismo. La ética en un mundo de extraños. Buenos Aires, Katz, 2007.

AugÉ, Marc. La vida en doble. Etnología, viaje y escritura. Buenos Aires, Paidós, 2012. 
BARRANCOS, Dora. Mujeres en la sociedad argentina, una historia de cinco siglos. Buenos Aires, Sudamericana, 2007.

. Estudios de género y renovación de las Ciencias Sociales en Argentina. Revistas Horizontes Sociológicos 1(6), Buenos Aires, AAS, 2013, pp.224-237.

BARTHES, Roland. Fragmentos de un discurso amoroso. Buenos Aires, Siglo XXI, 2002.

BellucCI, Mabel. Historia de una desobediencia. Aborto y feminismo. Buenos Aires, Capital Intelectual, 2014.

BERTAUX, Daniel. Los relatos de vida, perspectiva etnosociológica. Barcelona, Bellaterra, 2005.

BlANCO, Rafael. Del fulgor al desencanto. Desafíos para el feminismo académico en la fugaz experiencia de la Cerrara de Estudios de la Mujer (Universidad de Buenos Aires). Revista Interdisciplinaria de Estudios de Género de El Colegio de México vol. 4, Ciudad de México, COLMEX, 2018 , pp.1-31. [http://estudiosdegenero.colmex.mx/index.php/eg/article/view/159 acceso: 10 sept. 2018].

- Trayectorias académicas en los estudios sobre géneros y sexualidades: tensiones entre profesionalización, activismo y experiencia biográfica. Educação e Pesquisa, 42 (3), 2016. pp.727740 [http://www.redalyc.org/articulo.oa?id=29847323010_2 - 10 jul. 2018].

; VOMMARO, Pablo. Otros caminos, otros destinos. Transformaciones en los espacios y prácticas cotidianas de participación juvenil en los años ochentas, In: VOMMARO, P., VÁZQUEZ, M., NUÑEZ, P. y BlanCO, R. (comp.). Militancias juveniles en la Argentina democrática. Trayectorias, espacios y figuras de activismo. Buenos Aires, Ediciones Imago Mundi, 2017, pp.1-25.

BourdieU, Pierre. Homo academicus. Buenos Aires, Siglo XXI, 2012.

CARLI, Sandra. El viaje de conocimiento en las humanidades y las ciencias sociales. Un estudio de caso sobre profesores universitarios en la Argentina durante la segunda mitad del siglo XX. Historia de la Educación vol. 14, n 2, Anuario, Buenos Aires, SAHE, 2013, pp.138. 
FEMENÍAs, María Luisa. El feminismo académico en Argentina. Labrys. Estudos Feministas $\mathrm{n}^{\circ} \quad 7, \quad$ Brasilia, 2005 [http://www.labrys.net.br/labrys7/fem/mluisa.htm - 10 jul. 2018].

FREIDIN, Betina. El uso del enfoque biográfico para el estudio de las experiencias migratorias femeninas. In: SAUTU, Ruth (comp.). El método biográfico. La reconstrucción de la sociedad a partir del testimonio de los actores. Buenos Aires, Lumiere, 2004, pp.121-153.

GARCíA Somoza, Mari-Sol; IRRAZÁBAL, Gabriela. Géneros, sexualidades y religiones, relaciones, intersecciones y confrontaciones. Sociedad y religión 24(42), Buenos Aires, CEIL-CONICET, 2014, pp.132-143.

GARCÍA, Susana. El curriculum vitae, entre perfiles deseados y trayectorias negadas. Revista Iberoamericana de Educación Superior (RIES) vol. 1, n 1, México, ISSUE-UNAM/Universia, 2010, pp.103119.

GoGNA, Mónica; PECHENY, Mario; JONES, Daniel. Enseñanza sobre género y sexualidad en universidades públicas en la Argentina. In: ORTIZ ORTEGA, Adriana; PECHENY, Mario (coord.). Enseñanza universitaria sobre género y sexualidades en Argentina, Chile, China, México y Sudáfrica. Buenos Aires, Teseo, 2010, pp.153-191.

HeIlborn, Maria Luiza; CARRARA, Sergio. Prólogo. In: GognA, Mónica. Estado del arte, investigación sobre sexualidad y derechos en la Argentina (1990-2002). Buenos Aires, CEDES-CLAM, 2005, pp.9-11.

LÉVI-STRAuSS, Claude. Tristes trópicos. Barcelona, Paidós, 2006.

OREGIONI, María Soledad; SARTHOU, Nerina. La dinámica de la relación entre CONICET y dos universidades nacionales argentinas. Ciencia, Docencia y Tecnología n 46, Entre Ríos, UNER, mayo, 2013, pp.3368.

PALmeIRO, Cecilia. Derivas de lo queer en la Argentina, hacia una genealogía. Revista Periódicus vol. 1, $\mathrm{n}^{\circ}$ 1. Salvador, BA, UFSB, 2014, pp.21-42.

REMEDI, Eduardo; Blanco, Rafael. Devenir científico. Prácticas laterales, instituciones transicionales y figuras de identificación en la conformación de trayectorias exitosas. In: REMEDI, Eduardo; RAMíREZ GARCÍA, Rosalba (coord.). Los científicos y su quehacer Perspectivas 
en los estudios sobre trayectorias, producciones y prácticas científicas. Ciudad de México, IUNES, 2016. pp.385- 412.

SARlo, Beatriz. Viajes. De la Amazonia a las Malvinas. Buenos Aires, Seix Barral, 2014.

SPIVAK L'HOSTE, Ana; HuberT, Matthieu. Movilidad científica y reflexividad. De cómo los desplazamientos de los investigadores modelan modos de producir conocimientos. Redes vol. $18, \mathrm{n}^{\circ} 34$, Quilmes, UNQ, junio, 2012, pp.85-111.

VAgGione, Juan Marco. Prólogo. In: FigARI, Carlos; JonES, Daniel; BARRÓN LÓPEZ, Sara (comp.). La producción de la sexualidad. Políticas y regulaciones sexuales en Argentina. Buenos Aires, Biblos, 2012, pp.9-17. 